\title{
The effect of cocoa supplementation on hepatic steatosis, reactive oxygen species and LFABP in a rat model of NASH
}

\author{
Mile Janevski ${ }^{1}$, Kiriakos N Antonas², Melanie J Sullivan-Gunn¹, Maree A McGlynn³ and Paul A Lewandowski ${ }^{*}$
}

\begin{abstract}
Background: Non alcoholic steatohepatitis is hypothesised to develop via a mechanism involving fat accumulation and oxidative stress. The current study aimed to investigate if an increase in oxidative stress was associated with changes in the expression of liver fatty acid binding protein in a rat model of non alcoholic steatohepatitis and whether cocoa supplementation attenuated those changes.

Methods: Female Sprague Dawley rats were fed a high fat control diet, a high fat methionine choline deficient diet, or one of four $12.5 \%$ cocoa supplementation regimes in combination with the high fat methionine choline deficient diet.

Results: Liver fatty acid binding protein mRNA and protein levels were reduced in the liver of animals with fatty liver disease when compared to controls. Increased hepatic fat content was accompanied by higher levels of oxidative stress in animals with fatty liver disease when compared to controls. An inverse association was found between the levels of hepatic liver fatty acid binding protein and the level of hepatic oxidative stress in fatty liver disease. Elevated NADPH oxidase protein levels were detected in the liver of animals with increased severity in inflammation and fibrosis. Cocoa supplementation was associated with partial attenuation of these pathological changes, although the severity of liver disease induced by the methionine choline deficient diet prevented complete reversal of any disease associated changes. Red blood cell glutathione was increased by cocoa supplementation, whereas liver glutathione was reduced by cocoa compared to methionine choline deficient diet fed animals.
\end{abstract}

Conclusion: These findings suggest a potential role for liver fatty acid binding protein and NADPH oxidase in the development of non alcoholic steatohepatitis. Furthermore, cocoa supplementation may have be of therapeutic benefit in less sever forms of NASH.

Keywords: Non alcoholic steatohepatitis, NASH, oxidative stress, antioxidant, liver fatty acid binding protein, NADPH oxidase, cocoa

\section{Background}

Non alcoholic fatty liver disease (NAFLD) involves a spectrum of conditions ranging from simple fat accumulation in the liver to end stage liver failure and cirrhosis. NAFLD can lead into the development of non alcoholic steatohepatitis (NASH) [1]. NASH is an emerging health concern and it is believed that its prevalence is on the rise due to escalating obesity rates [2]. Estimated

\footnotetext{
* Correspondence: paul.lewandowski@deakin.edu.au

${ }^{1}$ School of Medicine, Deakin University, Waurn Ponds, Australia

Full list of author information is available at the end of the article
}

NAFLD prevalence in Western countries is between $17-$ $33 \%$ [3]. NAFLD accounts for up to $20 \%$, and NASH accounts for $2-3 \%$ of liver test abnormalities in most developed countries [4].

NASH is typically reported in obese individuals suffering from one or a combination of type 2 diabetes, insulin resistance and dyslipidaemia, but is not restricted to this group [2]. There is often an increase in aspartate aminotransferase (AST) and alanine aminotransferase (ALT) [5]. Lipid accumulation occurs early in NASH as part of the development of the disease [6]. The two hit
C Biomed Central 
disease model postulates that steatosis is a trigger for the establishment of NASH and the increased levels of fat infiltration cause damage to the liver by forming fat droplets within the hepatic tissue, thus setting off the second hit of the disease by causing lipotoxicity. In addition, cytokines and reactive oxygen species (ROS) create a pro-oxidant state that can activate stellate cells to produce fibrotic scar tissue [7].

Liver fatty acid binding protein (LFABP) accounts for $3-5 \%$ of the cytosolic protein content in hepatocytes. LFABP is transcriptionaly regulated by the nuclear hormone receptor, peroxisome proliferator-activated protein $\alpha$ (PPAR- $\alpha)$, and is responsible for intracellular trafficking of long chain fatty acids [8]. Rat LFABP has recently been described as an endogenous antioxidant [9], and may be useful in states of extreme oxidative stress when intracellular antioxidants such as superoxide dismutase, glutathione and catalase cannot quench excessive quantities of ROS. This antioxidant characteristic of LFABP is thought to result from the methionine groups located in the cavity of the LFABP binding site [9].

NADPH oxidase (NOX), an enzyme complex responsible for generating superoxide, is activated in rat Kupffer cells in alcoholic liver disease, through induction of transcription factor NF- $\kappa \beta$ and TNF- $\alpha$ production [10]. However, administration of a methionine choline deficient (MCD) diet to $\mathrm{p} 47$ knockout mice, lacking a critical subunit of the NOX complex, showed that NOX is not an important contributor of oxidative stress generation. The p47 knockout mice on an MCD diet developed NASH with similar pathology as wild type, despite the lack of a functional NOX enzyme [11].

Currently the only effective therapy to treat NAFLD and NASH is to decrease body weight in obese and overweight individuals, decrease circulating lipids, improve insulin sensitivity and decrease oxidative damage through the use of antioxidants [12]. Cocoa and some of its derivatives are a rich source of the flavonoid antioxidants, catechin and epicatechin [13]. In a high fat diet model of obesity, rats supplemented with cocoa had normalised insulin resistance and decreased weight gain. Furthermore, cocoa supplementation decreased gene expression of fatty acid binding protein in mesenteric adipose tissue [14]. Consumption of dark chocolate by human subjects for 15 days has been reported to improve blood pressure and insulin sensitivity [15]. Cocoa supplementation has been found to have a beneficial effect in a rat model of alcoholic steatohepatitis by reducing hepatic fat accumulation, inflammation and necrosis [16].

The current study aimed to investigate if an increase in oxidative stress was associated with changes in the expression of LFABP and NOX in a rat model of non alcoholic steatohepatitis and whether cocoa supplementation attenuated those changes.

\section{Methods}

\section{Animals and diet}

All animal experiments and procedures were approved by the animal welfare committee at Deakin University, approval number A36/2007. Twelve week old female Sprague Dawley rats $(\mathrm{n}=56$, Animal Resources Centre, Perth, Australia) were housed in pairs with ad libitum access to food and water. Female rats were selected to minimise fighting within pairs throughout the study. Three isocalorically matched diets were used in these investigations (Table 1). A high fat methionine choline sufficient (MCS) diet (control); a high fat methionine choline deficient (MCD) diet; and a high fat methionine choline deficient diet supplemented with $12.5 \%$ cocoa powder (MCS: A02082003B; MCD: A02082002B; Research Diets, New Brunswick, USA). The cocoa powder (Natraceutical, Valencia, Spain) contained $12 \%$ polyphenols, primarily catechin, and trace amounts of methionine $(0.28 \mathrm{mg} / \mathrm{g}$ diet $)$ and choline $(0.02 \mathrm{mg} / \mathrm{g}$ diet). The MCD diet is a commonly used model of $\mathrm{NASH}$ and is known to cause weight loss [7]. A pilot study demonstrated that a period of 52 days was a suitable time frame to induce NAFLD, based on histological grading, and still maintain the body weight of rats fed the MCD diet. The pilot study indicated that histologically the livers of rats fed the MCD diet were the same after 42 days of feeding through to 112 days of feeding. Rats were divided into six groups (Table 2) and were fed either a MCS or MCD diet for 52 days or one of four cocoa supplementation regimes: 52 days of MCD and an additional 28 days of MCD with cocoa supplementation (C1); 52 days of MCD and an additional 56 days of MCD with cocoa supplementation (C2); 80 days of MCD with cocoa supplementation (C3); 108 days of MCD with cocoa supplementation (C4). The four feeding regimes were selected to represent treatment or prevention supplementation modes that could be applied to NASH patients. Feeding regimes $\mathrm{C} 1$ and $\mathrm{C} 2$ were used to test if cocoa supplementation for four or eight weeks could be used to treat NASH after the disease was established. Whereas, feeding regimes $\mathrm{C} 3$ and $\mathrm{C} 4$ were used to see if cocoa supplementation could be used to prevent or slow the development of NASH over the same total time periods used in regimes $\mathrm{C} 1$ and $\mathrm{C} 2$.

At the conclusion of each regime, animals were fasted overnight and euthanized at 8 am via a lethal dose of anaesthetic (70 mg/kg Lethabarb, Therapon, Melbourne, Australia). Blood samples were collected via cardiac puncture and the liver, heart, kidneys and pancreas removed and weighed. One lobe of the liver was fixed in $4 \%$ paraformaldehyde (Sigma, Sydney, Australia) and the remaining portion snap frozen and stored at $-80^{\circ} \mathrm{C}$ for further analysis. 
Table 1 Diet composition

\begin{tabular}{|c|c|c|c|}
\hline Catalogue number & A02082002B & A02082003B & $\begin{array}{c}\text { A07071301 } \\
\text { Cocoa (C1 - C4) }\end{array}$ \\
\hline & & & \\
\hline Protein & 17 & 17.2 & 17 \\
\hline Carbohydrate & 65.9 & 65.5 & 65.9 \\
\hline Fat & 9.9 & 9.9 & 9.9 \\
\hline L-Alanine & 3.5 & 3.5 & 2.9 \\
\hline L-Arginine & 12.1 & 12.1 & 9.9 \\
\hline L-Asparagine- $\mathrm{H}_{2} \mathrm{O}$ & 6 & 6 & 4.9 \\
\hline L-Aspartate & 3.5 & 3.5 & 2.9 \\
\hline L-Cystine & 3.5 & 3.5 & 2.9 \\
\hline L-Glutamine & 40 & 40 & 32.8 \\
\hline Glycine & 23.3 & 23.3 & 19.1 \\
\hline L-Histidine- $\mathrm{HCl}-\mathrm{H}_{2} \mathrm{O}$ & 4.5 & 4.5 & 3.7 \\
\hline L-Isoleucine & 8.2 & 8.2 & 6.7 \\
\hline L-Leucine & 11.1 & 11.1 & 9.1 \\
\hline L-Lysine-HCl & 18 & 18 & 14.7 \\
\hline L-Phenylalanine & 7.5 & 7.5 & 6.1 \\
\hline L-Proline & 3.5 & 3.5 & 2.9 \\
\hline L-Serine & 3.5 & 3.5 & 2.9 \\
\hline L-Threonine & 8.2 & 8.2 & 6.7 \\
\hline L-Tryptophan & 1.8 & 1.8 & 1.5 \\
\hline L-Tyrosine & 5 & 5 & 4.1 \\
\hline L-Valine & 8.2 & 8.2 & 6.7 \\
\hline Total L-Amino Acids & 171.4 & 171.4 & 140.5 \\
\hline Sucrose & 455.3 & 452.3 & 455.3 \\
\hline Corn starch & 150 & 150 & 106 \\
\hline Maltodextrin & 50 & 50 & 50 \\
\hline Cellulose & 30 & 30 & 0 \\
\hline Corn oil & 100 & 100 & 86 \\
\hline Mineral mix S10001 & 35 & 35 & 35 \\
\hline Sodium bicarbonate & 7.5 & 7.5 & 7.5 \\
\hline Vitamin mix V10001 & 10 & 10 & 10 \\
\hline DL-Methionine & 0 & 3 & $0.2^{*}$ \\
\hline Choline bitrate & 0 & 2 & $0.017^{*}$ \\
\hline Cocoa powder & 0 & 0 & 144 \\
\hline Total & 1009.2 & 1011.2 & 1034.3 \\
\hline
\end{tabular}

High fat methionine choline sufficient (MCS) diet, high fat methionine choline deficient (MCD) diet, high fat methionine choline deficient diet with 28 days of cocoa supplementation (C1), high fat methionine choline deficient diet with 56 days of cocoa supplementation (C2), high fat methionine choline deficient diet supplemented with cocoa for 80 days (C3) and high fat methionine choline deficient diet supplemented with cocoa for 108 days (C4).

* Derived from cocoa powder.

\section{Histological analysis}

The liver histology was assessed on de-identified slides by two independent blinded observers after an initial consensus meeting. Haematoxylin and eosin (H\&E) (Thermo Scientific, Melbourne, Australia) stained sections were scored for steatosis (0-3) and lobular inflammation (0-3) according to the revised Kleiner method [17]. The presence or absence of portal inflammation was also noted (0-1). Fibrosis was graded (0-4) using Sirius Red (Sigma, Sydney, Australia) stained sections [17]. A random subset of $10 \%$ of cases was rescored by each observer. Each animal had duplicate histological specimens prepared, and where scores differed between duplicates, the slides were rescored for consensus.

\section{Biochemical parameters and measures of oxidative stress}

Plasma triglycerides and glucose levels were determined using appropriate assay kits according to the manufacturer's instructions (Thermo Scientific, Melbourne, Australia). Red blood cell (RBC) and liver tissue glutathione (GSH), an endogenous antioxidant, was measured via the GSH recycling method as previously described [18]. Briefly, RBC were obtained by centrifugation of blood $(1000 \times g)$ and $200 \mu \mathrm{l}$ of $\mathrm{RBC}$ was used; $1 \mathrm{~g}$ of liver was homogenized. A change in absorbance $(412 \mathrm{~nm})$ was determined after the addition of 5,5'-Dithiobis(2-nitrobenzoic acid) (Sigma, Sydney, Australia) and corrected to reduced L-glutathione standard (Sigma, Sydney, Australia). Liver GSH was corrected for protein concentration which was determined via the Bradford method (BioRad, Sydney, Australia). Dihydroethidium (DHE) staining (Sigma, Sydney, Australia) was used to detect levels of superoxide in liver cryosections $(14 \mu \mathrm{m})$ [19]. DHE fluorescence was quantified using a fluorescence quantification program, ImageJ (National Institutes of Health, USA), as a measure of superoxide levels present in tissue. An ELISA kit was used to measure the DNA oxidation byproduct 8-hydroxy-2-deoxy guanosine (8$\mathrm{OH}-2 \mathrm{dG}$ ) (StressMarq Biosciences). DNA was extracted from $15 \mathrm{mg}$ of liver tissue using a DNA isolation kit (Promega, Sydney, Australia). Each sample was then diluted so that $50 \mu \mathrm{g}$ of DNA was used in the 8-OH$2 \mathrm{dG}$ assay. The competitive immunoassay involves the binding of free 8-OH-2dG to an antibody coated 96 well plate. The assay and sample concentration of 8 $\mathrm{OH}-2 \mathrm{dG}$ were carried out as per the manufacturer's instructions. Total 8-isoprostane concentrations were analysed as a marker of oxidative damage to lipids in liver homogenates prepared for liver GSH using an enzyme immunoassay (EIA) kit (Cayman Chemicals, Sydney, Australia) following manufactures instructions. Prior to analysis liver homogenates were hydrolysed by addition of $25 \mu \mathrm{l} 2 \mathrm{M} \mathrm{NaOH}$ to each $100 \mu \mathrm{l}$ homogenate. The samples were incubated at $45^{\circ} \mathrm{C}$ for 2 hours. Following this, $25 \mu \mathrm{l} 10 \mathrm{~N} \mathrm{HCl}$ acid was added and the samples were centrifuged for 5 minutes at $12,000 \mathrm{~g}$. The supernatant was removed and used for the determination of total 8-isoprostane using the EIA kit. The assay was based on the competition between 8-isoprostane and an 8-isoprostane acetycholinesterase (AChE) conjugate for a limited number of 8-iso-PGF2 $\alpha$-specific rabbit anti-serum binding sites, values were expressed as $\mathrm{pg} /$ mg of protein. 
Table 2 Experimental groups, diets and duration of each diet regime

\begin{tabular}{ccccc}
\hline Diet & Diet regimes & MCS duration (days) & MCD duration (days) & MCD and cocoa duration (days) \\
\hline MCS & High fat MCS & 52 & - & - \\
MCD & High fat MCD & - & 52 & - \\
C1 & High fat MCD followed by 28 day cocoa supplementation & - & 52 & 28 \\
C2 & High fat MCD followed by 56 day cocoa supplementation & - & 52 & 56 \\
C3 & High fat MCD with cocoa supplementation & - & - & 80 \\
C4 & High fat MCD with cocoa supplementation & - & - & 108 \\
\hline
\end{tabular}

High fat methionine choline sufficient (MCS) diet, high fat methionine choline deficient (MCD) diet, high fat methionine choline deficient diet with 28 days of cocoa supplementation (C1), high fat methionine choline deficient diet with 56 days of cocoa supplementation (C2), high fat methionine choline deficient diet supplemented with cocoa for 80 days (C3) and high fat methionine choline deficient diet supplemented with cocoa for 108 days (C4).

\section{RT-PCR}

Total RNA was extracted from $50 \mathrm{mg}$ of frozen liver using TRI reagent (Astral Scientific, Sydney, Australia) according to the manufacturer's specification. The total RNA concentration was determined by A260/A280 measurement. One microgram of total RNA was reverse transcribed into cDNA using AMV reverse transcriptase first strand cDNA synthesis kit according to the manufacturer's protocol (Marligen Biosciences, Sydney, Australia). Primers were designed using Primer3. Forward and reverse primer sequences are shown in Table 3. $\beta$ actin mRNA was quantified and showed no significant variation between feeding regimes, and all results were normalised to these values. The amplification of cDNA samples was carried out using IQ SYBR green ${ }^{\mathrm{TM}}$ following the manufacturers protocols (BioRad, Sydney, Australia) Fluorescent emission data was captured and mRNA levels were analyzed using the critical threshold (CT) value [20].Thermal cycling and fluorescence detection were conducted using the Biorad IQ50 sequence detection system (BioRad, Sydney, Australia).

\section{Protein extraction and western blot analysis}

Liver samples (100 mg) were homogenized and centrifuged at $10,000 \mathrm{~g}$ at $4^{\circ} \mathrm{C}$ for 10 minutes. The protein concentration was determined via the Bradford method (BioRad, Sydney, Australia); protein samples $(10 \mu \mathrm{g})$ were separated via SDS-PAGE on a 4-20\% gradient gel (NuSep, Sydney, Australia) and transferred onto

Table 3 Primer sequences

\begin{tabular}{ll}
\hline Target & Sequence \\
\hline$\beta$-actin & Forward- TGT CAC CAA CTG GGA CGA TA \\
& Reverse- AAC ACA GCC TGG ATG GCT AC \\
LFABP & Forward- CAT CCA GAA AGG GAA GGA CA \\
& Reverse- CAC GGA CTT TAT GCC TIT GAA \\
NOX1 & Forward- TAC GAA GTG GCT GTA CTG GTT G \\
& Reverse- CTC CCA AAG GAG GTT TTC TGT T \\
NOX2 & Forward- TCA AGT GTC CCC AGG TAT CC \\
NOX4 & Reverse- CTT CAC TGG CTG TAC CAA AGG \\
& Forward- GGA AGT CCA TT GAG GAG TCA C \\
& Reverse- TGG ATG TTC ACA AAG TCA GGT C
\end{tabular}

polyvinylidene difluoride membranes. The membranes were treated as previously described [21]. Proteins were visualised using Immune-Star HRP substrate kit (BioRad, Sydney, Australia). The density of the bands was quantified using a Chemidoc system (BioRad, Sydney, Australia) and normalised to $\beta$-actin expression. LFABP primary antibody used was a rabbit polyclonal antibody (1:200). NOX1 primary antibody used was a rabbit polyclonal antibody (1:200). Secondary antibody used for both LFABP and NOX1 was a goat anti-rabbit IgG-HRP conjugated antibody (1:5000). $\beta$-actin primary antibody, mouse anti $\beta$-actin (1:200) and secondary goat anti mouse antibody (1:2000) were used. Antibodies were purchased from Santa Cruz Biotechnology (CA, USA).

\section{Statistical analysis}

Statistical analysis was performed using SPSS analysis package (version 17.0), with independent t-tests and ANOVA with Tukey post-hoc analysis. The categorical assignments of the various histological aspects of NASH were statistically analysed by Fishers Exact test. Values were expressed as mean \pm SEM and considered statistically significant with a $p \leq 0.05$.

\section{Results}

\section{Histological analysis}

The results of the scoring of each of the histological variables for each of the groups are presented as percentages in Table 4. Histological analysis showed very little difference in observed steatosis or fibrosis between most of the groups (Table 4), with a few notable exceptions. A statistically significant higher steatosis score was seen in livers from animals fed the MCD diet compared to animals fed the MCS diet - which showed no or minimal steatosis, scoring 0 (Table $4 p<0.001$ ). This high steatosis score seen with the pure MCD diet was also present in each of the cocoa supplemented diet regimes (again statistically different when compared to the MCS group, Table $4 p<0.001$ ), with the exception of the C3 diet regime - the livers of which showed a lesser degree of steatosis when compared to the $\mathrm{C} 1$ and $\mathrm{C} 2$ diet 
Table 4 NASH scoring of H\&E stained liver sections and fibrosis scores in Sirius Red stained liver sections

\begin{tabular}{|c|c|c|c|c|c|c|c|}
\hline & Score & $\begin{array}{c}\text { MCS } \\
\text { (\% of cases) }\end{array}$ & $\begin{array}{c}\text { MCD } \\
\text { (\% of cases) }\end{array}$ & $\begin{array}{c}\mathrm{C} 1 \\
\text { (\% of cases) }\end{array}$ & $\begin{array}{c}\text { C2 } \\
\text { (\% of cases) }\end{array}$ & $\begin{array}{c}\text { C3 } \\
\text { (\% of cases) }\end{array}$ & $\begin{array}{c}\text { C4 } \\
\text { (\% of cases) }\end{array}$ \\
\hline \multirow[t]{4}{*}{ Steatosis } & 0 & $100 \%$ & $0 \%$ & $0 \%$ & $0 \%$ & $0 \%$ & $0 \%$ \\
\hline & 1 & $0 \%$ & $13 \%$ & $0 \%$ & $0 \%$ & $31 \%$ & $12 \%$ \\
\hline & 2 & $0 \%$ & $17 \%$ & $0 \%$ & $0 \%$ & $50 \%$ & $19 \%$ \\
\hline & 3 & $0 \%$ & $70 \%$ & $100 \%$ & $100 \%$ & $19 \%$ & $69 \%$ \\
\hline Significant & & $\mathrm{MCD}, \mathrm{C1}, \mathrm{C2}, \mathrm{C} 3, \mathrm{C} 4$ & MCS, C3 & MCS, C3 & MCS, C3 & MCS, MCD, C1, C2 & MCS \\
\hline \multirow[t]{2}{*}{ Portal inflammation } & 0 & $88 \%$ & $83 \%$ & $69 \%$ & $21 \%$ & $94 \%$ & $94 \%$ \\
\hline & 1 & $12 \%$ & $17 \%$ & $31 \%$ & $79 \%$ & $6 \%$ & $6 \%$ \\
\hline Significant & & $\mathrm{C} 2$ & $\mathrm{C} 2$ & $\mathrm{C} 2$ & MCS, MCD, C1, C3, C4 & $C 2$ & $\mathrm{C} 2$ \\
\hline \multirow[t]{4}{*}{ Lobular inflammation } & 0 & $27 \%$ & $8 \%$ & $0 \%$ & $0 \%$ & $19 \%$ & $0 \%$ \\
\hline & 1 & $67 \%$ & $4 \%$ & $13 \%$ & $13 \%$ & $31 \%$ & $31 \%$ \\
\hline & 2 & $2 \%$ & $57 \%$ & $64 \%$ & $64 \%$ & $50 \%$ & $56 \%$ \\
\hline & 3 & $4 \%$ & $31 \%$ & $23 \%$ & $23 \%$ & $0 \%$ & $13 \%$ \\
\hline Significant & & $M C D, C 2$ & MCS & $N / S$ & MCS & $N / S$ & $N / S$ \\
\hline \multirow[t]{7}{*}{ Fibrosis } & 0 & $12.5 \%$ & $0 \%$ & $0 \%$ & $0 \%$ & $0 \%$ & $0 \%$ \\
\hline & $1 \mathrm{~A}$ & $0 \%$ & $18.8 \%$ & $0 \%$ & $0 \%$ & $0 \%$ & $0 \%$ \\
\hline & $1 \mathrm{~B}$ & $87.5 \%$ & $62.5 \%$ & $12.5 \%$ & $14.3 \%$ & $62.5 \%$ & $37.5 \%$ \\
\hline & $1 C$ & $0 \%$ & $0 \%$ & $0 \%$ & $0 \%$ & $0 \%$ & $0 \%$ \\
\hline & 2 & $0 \%$ & $6.3 \%$ & $62.5 \%$ & $0 \%$ & $37.5 \%$ & $50 \%$ \\
\hline & 3 & $0 \%$ & $12.5 \%$ & $25 \%$ & $85.7 \%$ & $0 \%$ & $12.5 \%$ \\
\hline & 4 & $0 \%$ & $0 \%$ & $0 \%$ & $0 \%$ & $0 \%$ & $0 \%$ \\
\hline Significant & & $\mathrm{MCD}, \mathrm{C1}, \mathrm{C2}, \mathrm{C} 3, \mathrm{C} 4$ & MCS, C1, C2, C3, C4 & MCS, MCD, C2, C3, C4 & MCS, MCD, C1, C3, C4 & $\mathrm{MCS}, \mathrm{MCD}, \mathrm{C1}, \mathrm{C2}, \mathrm{C} 4$ & MCS, MCD, C1, C2, C3 \\
\hline
\end{tabular}

Steatosis (0-3), portal inflammation (0-1), lobular inflammation (0-3) and fibrosis (0-4). Groups that are significantly different are listed below values, $p<0.05$. 
regimes (Table $4 p=0.007$ ). The presence of portal inflammation largely paralleled the degree of portal fibrosis, and each of these was most pronounced in the C2 group (Table $4 \mathrm{p}<0.001$ ). Lobular inflammation was seen across the board in the MCD and cocoa supplemented diets to a relatively similar degree, but there was only weak statistical significance in this observation for some of the groups when compared to the degree of lobular inflammation in the MCS group (Table $4 \mathrm{p}<$ $0.05)$. The lowest fibrosis scores were seen in the MCS group (Table $4 \mathrm{p}<0.05$ ), and compared to the other cocoa supplementation groups, the livers from the animals on the $\mathrm{C} 3$ diet had the lowest fibrosis scores (Table $4 \mathrm{p}<0.05$ ). Cirrhosis (Fibrosis score 4) was not seen in any of the livers from any of the animals in this study (Figure 1; Table 4).

\section{Organ weight and body weight}

Animals on the MCD and $\mathrm{C} 1-\mathrm{C} 4$ diet regimes had lower body weight compared to MCS animals (Table $5 p<$ $0.001)$. Heart, kidney and pancreas weight were the same for all groups (data not shown). In contrast, liver weight represented a greater portion of body weight in the MCD and $\mathrm{C} 1-\mathrm{C} 4$ diet regimes compared to rats fed the MCS diet (Table $5 p<0.001$ ). In addition, liver weight was significantly lower in the $\mathrm{C} 2$ diet regime (3.7 $\pm 0.1 \%$ ) when compared to the MCD, C3 and C4 diet regimes, $4.4 \pm 0.1 \%, 5.2 \pm 0.2 \%$ and $4.1 \pm 0.1 \%$, respectively (Table $5 p<0.01$ ). Average food intake over the duration of each dietary regime was in line with body weight; food intake did not differ between the cocoa regimes (Table 5).

\section{Biochemical parameters}

Circulating triglyceride levels were lower following consumption of the MCD diet when compared to the MCS diet (Table $5 p<0.001$ ). This lower level was enhanced by the administration of cocoa supplement, resulting in a lower level of circulating triglycerides when compared to the MCD diet (Table $5 p<0.01$ ). Duration of cocoa supplement enhanced this effect with $\mathrm{C} 2$ resulting in lower triglyceride levels when compared to C1 (Table $5 p=0.02$ ).

Circulating glucose levels were also lower in animals on the MCD diet irrespective of cocoa supplementation when compared to MCS (Table $5 p<0.05$ ). C1 and C2 resulted in significantly lower glucose when compared to $\mathrm{C} 3$ (Table $5 p<0.01$ ).

\section{Measures of oxidative stress}

Superoxide (DHE) levels were significantly higher in MCD fed animals compared to MCS fed animals (Table $5 p<0.001)$. Furthermore, superoxide levels were two fold higher in the $\mathrm{C} 1, \mathrm{C} 2$ and $\mathrm{C} 4$ groups when compared to animals fed the MCS diet (Table $5 p<0.001$ ). C3 had the lowest superoxide levels when compared to the other cocoa groups (Table $5 p<0.01$ ).

Liver GSH was twofold higher in MCD animals when compared to MCS diet fed animals (Table $5 p<0.01$ ). Liver GSH was observed to be lower in all cocoa groups when compared to MCD (Table $5 p<0.001$ ). In addition, $\mathrm{C} 4$ had significantly higher liver GSH when compared to the $\mathrm{C} 1$ and $\mathrm{C} 3$ diet regimes (Table $5 p<0.05$ ).

Animals on the MCS diet had significantly lower RBC GSH when compared to those on the MCD and cocoa regimes (Table $5 p<0.01$ ), with the exception of animals on the $\mathrm{C} 4$ diet regime. Animals on the $\mathrm{C} 1$ and $\mathrm{C} 2$ diet regimes had significantly higher RBC GSH levels, two fold and three fold respectively, when compared to MCS, MCD, C3 and C4 diet regimes (Table $5 p<0.01$ ).

Liver 8-OH-2dG levels were significantly lower in MCD fed animals compared to MCS fed animals (Table $5 p<0.04)$. In contrast there was a significantly higher level of $8-\mathrm{OH}-2 \mathrm{dG}$ in groups $\mathrm{C} 1$ and $\mathrm{C} 2$ compared to MCS and MCD fed animals (Table $5 p<0.001$ ). Whereas, 8-OH-2dG levels in groups $\mathrm{C} 3$ and $\mathrm{C} 4$ were significantly lower than the levels observed in $\mathrm{C} 1$ and C2 (Table $5 p<0.001$ ).

Liver 8-isoprostane levels were significantly higher in MCD fed animals and group C2 compared to MCS fed animals (Table $5 p<0.02$ ). In contrast C3 has significantly lower levels of 8 -isoprostane compared to MCD and $\mathrm{C} 2$ groups (Table $5 p<0.03$ ).

\section{LFABP mRNA and Protein Expression}

Lower levels of LFABP mRNA were observed following MCD diet consumption when compared to the MCS diet (Figure 2A, $\mathrm{p}<0.001$ ), but LFABP mRNA was 56 fold higher in animals fed the $\mathrm{C} 1$ diet when compared to the MCD diet (Figure 2A, p < 0.01). There was 20 fold lower LFABP protein levels in animals fed the MCD when compared to the MCS diet (Figure 2B, p < 0.001). The animals fed the MCS diet had higher levels of LFABP protein when compared to $\mathrm{C} 2, \mathrm{C} 3$ and $\mathrm{C} 4$ diet regimes (Figure $2 \mathrm{~B}, \mathrm{p}<0.001$ ). The $\mathrm{C} 1$ diet regime also showed higher levels of LFABP protein when compared to MCD (Figure 2B, $\mathrm{p}<0.01$ ).

\section{NOX mRNA and Protein Expression}

A fivefold depression of the NOX1 mRNA was observed following MCD diet consumption, with or without cocoa supplementation, when compared to the MCS diet (Figure 3A, p < 0.05). No difference was found in the mRNA levels of NOX2 and NOX4 between diet regimes. NOX1 protein levels were 20 fold higher in the $\mathrm{C} 2$ group when compared to MCS, 

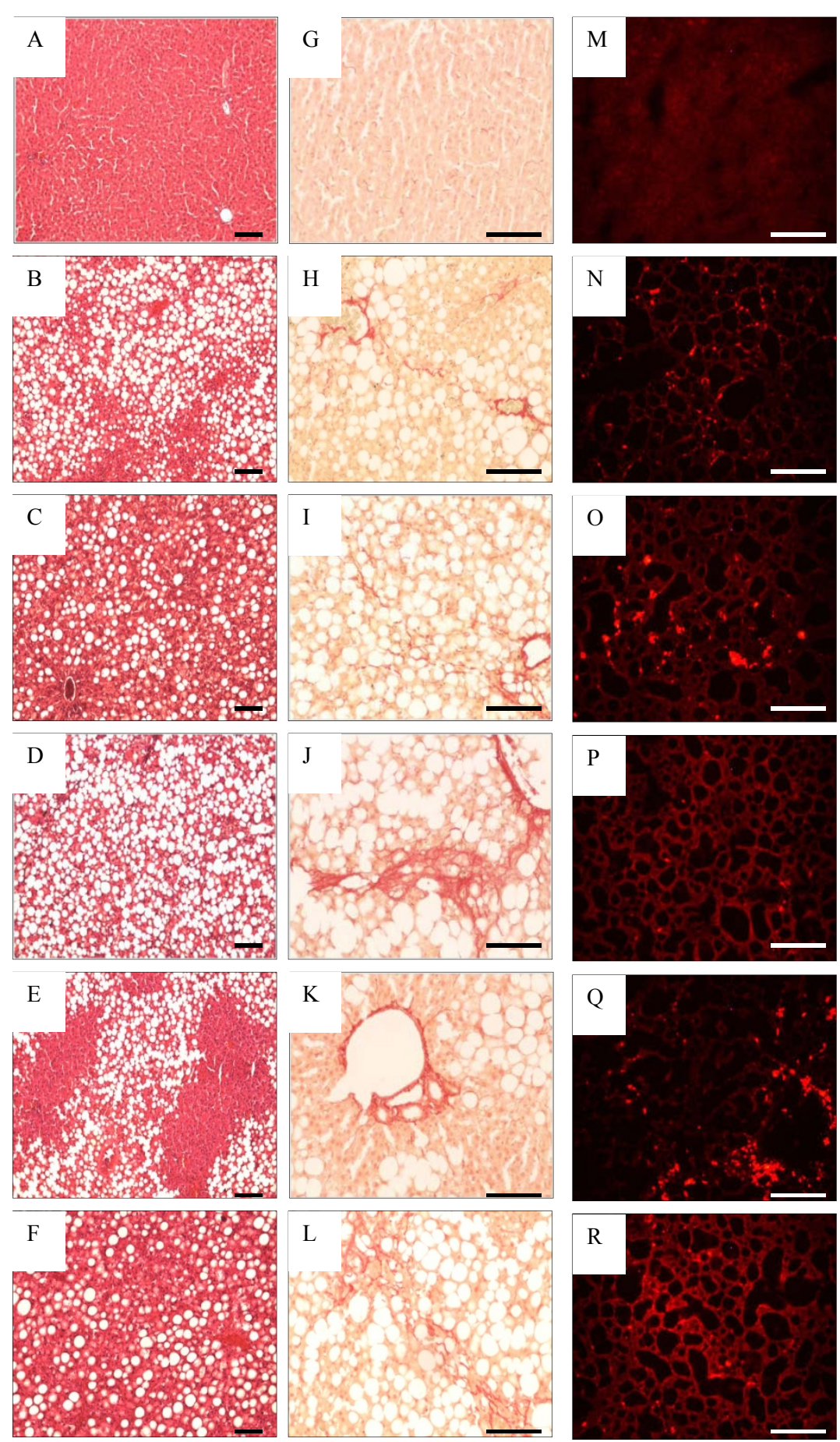

Figure 1 Histological examination of liver sections by H\&E stain (at left), Sirius Red stain (at middle) and DHE stain (at right). H\&E stain $(A-F)$ : MCS diet (A), MCD diet (B), C1 (C), C2 (D), C3 (E), C4 (F). Sirius Red stain of fibrosis (G-L): MCS diet (G), MCD diet (H), C1 (I), C2 (J), C3 (K), C4 (L). DHE stain of superoxide (M-R): MCS diet (M), MCD diet (N), C1 (O), C2 (P), C3 (Q), C4 (R). Bar = $100 \mu \mathrm{m}$.

$\mathrm{MCD}, \mathrm{C} 1, \mathrm{C} 3$ and $\mathrm{C} 4$ diet regimes (Figure 3B, $\mathrm{p}<$ $0.01)$. Both $\mathrm{C} 3$ and $\mathrm{C} 4$ diet regimes had significantly higher NOX1 protein levels compared to the MCD diet (Figure 3B, $\mathrm{p}<0.03$ ).

\section{Discussion}

The present study was carried out to determine if oxidative stress was associated with changes in the expression of LFABP and NOX in a rat model of non alcoholic 
Table 5 Biochemical parameters and measures of oxidative stress

\begin{tabular}{|c|c|c|c|c|c|c|}
\hline & MCS & MCD & C1 & $\mathrm{C} 2$ & $\mathrm{C} 3$ & $\mathrm{C} 4$ \\
\hline Food intake (g/pair/day) & $24.4 \pm 1.6$ & $\begin{array}{l}16.4 \pm 0.5 \\
\text { MCS }\end{array}$ & $\begin{array}{l}13.4 \pm 0.4 \\
\text { MCS }\end{array}$ & $\begin{array}{l}13.8 \pm 0.6 \\
\text { MCS }\end{array}$ & $\begin{array}{l}12.4 \pm 1.5 \\
\text { MCS }\end{array}$ & $\begin{array}{c}9.6 \pm 0.5 \\
\text { MCS, MCD }\end{array}$ \\
\hline $\begin{array}{l}\text { Body weight } \\
\text { (g) }\end{array}$ & $283 \pm 10$ & $\begin{array}{c}185 \pm 4 \\
\text { MCS }\end{array}$ & $\begin{array}{c}192 \pm 3 \\
\text { MCS }\end{array}$ & $\begin{array}{l}195 \pm 7 \\
\text { MCS }\end{array}$ & $\begin{array}{c}188 \pm 5 \\
\text { MCS }\end{array}$ & $\begin{array}{l}184 \pm 5 \\
\text { MCS }\end{array}$ \\
\hline Liver/body weight (\%) & $2.7 \pm 0.1$ & $\begin{array}{l}4.4 \pm 0.1 \\
\text { MCS }\end{array}$ & $\begin{array}{c}4.5 \pm 0.3 \\
\text { MCS }\end{array}$ & $\begin{array}{l}3.7 \pm 0.1 \\
M C S, M C D\end{array}$ & $\begin{array}{l}5.2 \pm 0.2 \\
\text { MCS, C2 }\end{array}$ & $\begin{array}{l}4.1 \pm 0.1 \\
\text { MCS, C2 }\end{array}$ \\
\hline $\begin{array}{c}\text { DHE } \\
\text { (arbitrary units) }\end{array}$ & $42.3 \pm 2.1$ & $\begin{array}{c}71.6 \pm 3.6 \\
\text { MCS }\end{array}$ & $\begin{array}{l}88.1 \pm 1.0 \\
\text { MCS }\end{array}$ & $\begin{array}{l}87.9 \pm 1.0 \\
\text { MCS }\end{array}$ & $\begin{array}{c}74.8 \pm 3.7 \\
\text { MCS, C1, C2 }\end{array}$ & $\begin{array}{l}88.8 \pm 2.5 \\
M C S, C 3\end{array}$ \\
\hline $\begin{array}{l}\text { Liver } 8-\mathrm{OH}-2 \mathrm{dG} \\
\quad(\mathrm{pg} / \mathrm{ml})\end{array}$ & $192 \pm 12$ & $\begin{array}{l}145 \pm 5 \\
\text { MCS }\end{array}$ & $\begin{array}{c}265 \pm 14 \\
\text { MCS, MCD }\end{array}$ & $\begin{array}{c}304 \pm 12 \\
\text { MCS, MCD }\end{array}$ & $\begin{array}{c}205 \pm 8 \\
M C D, C 1, C 2\end{array}$ & $\begin{array}{c}172 \pm 7 \\
C 1, C 2\end{array}$ \\
\hline $\begin{array}{l}\text { Liver 8-isoprostane } \\
\text { (pg/mg protein) }\end{array}$ & $110 \pm 12$ & $\begin{array}{l}155 \pm 7 \\
\text { MCS }\end{array}$ & $137 \pm 9$ & $\begin{array}{c}163 \pm 12 \\
\text { MCS }\end{array}$ & $\begin{array}{l}121 \pm 5 \\
M C D, C 2\end{array}$ & $157 \pm 7$ \\
\hline $\begin{array}{l}\text { Liver GSH } \\
\quad(\mathrm{mg})\end{array}$ & $495 \pm 64$ & $\begin{array}{l}1090 \pm 156 \\
\text { MCS }\end{array}$ & $\begin{array}{c}120 \pm 8 \\
\text { MCD }\end{array}$ & $\begin{array}{c}127 \pm 9 \\
\text { MCD }\end{array}$ & $\begin{array}{c}106 \pm 10 \\
M C D\end{array}$ & $\begin{array}{c}142 \pm 6 \\
M C D, C 1, C 3\end{array}$ \\
\hline $\begin{array}{l}\text { RBC GSH } \\
(\mathrm{mg})\end{array}$ & $144 \pm 8$ & $\begin{array}{c}177 \pm 7 \\
\text { MCS }\end{array}$ & $\begin{array}{l}359 \pm 26 \\
\text { MCS, MCD }\end{array}$ & $\begin{array}{l}432 \pm 70 \\
\text { MCS, MCD }\end{array}$ & $\begin{array}{c}193 \pm 15 \\
\text { MCS, C1, C2 }\end{array}$ & $\begin{array}{c}120 \pm 7 \\
C 1, C 2\end{array}$ \\
\hline $\begin{array}{l}\text { Glucose } \\
(\mathrm{mmol} / \mathrm{L})\end{array}$ & $9.1 \pm 0.4$ & $\begin{array}{c}6.8 \pm 0.1 \\
\text { MCS }\end{array}$ & $\begin{array}{c}6.5 \pm 0.2 \\
\text { MCS }\end{array}$ & $\begin{array}{c}6.0 \pm 0.2 \\
\text { MCS }\end{array}$ & $\begin{array}{c}7.7 \pm 0.1 \\
\text { MCS, C1, C2 }\end{array}$ & $\begin{array}{c}6.6 \pm 0.4 \\
\text { MCS }\end{array}$ \\
\hline Triglycerides (mmol/L) & $1.25 \pm 0.05$ & $\begin{array}{l}0.99 \pm 0.04 \\
\text { MCS }\end{array}$ & $\begin{array}{c}0.70 \pm 0.02 \\
\text { MCD }\end{array}$ & $\begin{array}{c}0.66 \pm 0.01 \\
M C D, C 1\end{array}$ & $\begin{array}{c}0.71 \pm 0.03 \\
\text { MCD }\end{array}$ & $\begin{array}{l}0.72 \pm 0.01 \\
\text { MCD }\end{array}$ \\
\hline
\end{tabular}

Values are presented as mean \pm SEM. Groups that are significantly different are listed below values, $p<0.05$.

steatohepatitis and whether cocoa supplementation attenuated those changes. The results indicate an association between the MCD diet and levels of LFABP in the development of NASH in a well established model of the disease. Levels of LFABP mRNA and protein were significantly lower in animals on the MCD diet in comparison to animals on the MCS diet. Suppression of LFABP may be another mechanism by which this diet causes an increased fat content in the liver in addition to impairing phosphatidylcholine synthesis [7]. Low levels of LFABP may lead to an inability of the hepatocyte to shuttle long chain fatty acids to different intracellular destinations for metabolism [22], resulting in higher levels of hepatic fat content in MCD animals as evident from the histological analysis (Figure 1; Table 4). Supplementation of MCD diet with cocoa in the $C 1$ diet regime significantly increased levels of LFABP mRNA (Figure 2A), which we postulate leads to a restoration in trafficking of fatty acids within the hepatocyte; however this did not lead to a lower degree of observed steatosis (Table 4). Increased levels of LFABP may reduce oxidative damage by binding long chain fatty acids to its methionine residues [23]. Low levels of LFABP in MCD fed animals may therefore result in increased oxidative damage due to its ability to act as an endogenous antioxidant [9]. The increase in LFABP mRNA in the $\mathrm{C} 1$ diet regime (Figure $2 \mathrm{~A}$ ) showed a similar pattern at the protein level (Figure 2B). A decrease in LFABP may be linked to the liver's inability to cope with lipotoxicity, which is thought to contribute to NASH [24]. LFABP has been found to be upregulated in the presence of long chain fatty acids and has been directly implicated in hepatic regeneration [25]. This may be correlated to the effects of LFABP stimulation of PPAR- $\alpha$ to further increase LFABP mRNA. Findings in rat models indicate an increase in LFABP during hepatic regeneration, supporting the role of this protein in maintaining the integrity of the hepatocyte [25]. LFABP deregulation, as shown by an inverse relationship between the ratio of LFABP and fat content in the liver, has been correlated with obesity and type 2 diabetes in the Israeli sand rat [26]. This is further supported by a silencing of LFABP in patients with hepatocellular adenoma who had a mutation in the hepatocyte nuclear factor $1 \alpha$, causing impaired trafficking of fatty acids, leading to steatosis [27]. Since LFABP is an abundant protein in hepatocytes, it may provide a major source of intracellular antioxidant activity. Purified LFABP has been tested for its antioxidant capacity [9] and is able to quench up to $66 \%$ of free radicals generated from superoxide. This is in agreement with our findings of lower LFABP being present at both the mRNA level (Figure 2A) and protein level (Figure 2B) in animals with MCD derived fatty liver disease in comparison to the animals fed the MCS diet. In addition, higher levels of superoxide fluorescence and 8-isoprostane were evident in the MCD fed animals as compared to the MCS fed animals (Table 3 and 5; Figure $1 \mathrm{M}$ and $1 \mathrm{~N}$ ), further supporting an inverse association between levels of LFABP and levels of oxidative stress. However, supplementation with cocoa in the $\mathrm{C} 1$ and $\mathrm{C} 2$ diet regimes resulted in higher superoxide and $8-\mathrm{OH}-$ $2 \mathrm{dG}$ levels when compared to MCS animals. This may be related to higher degree of observed steatosis in 

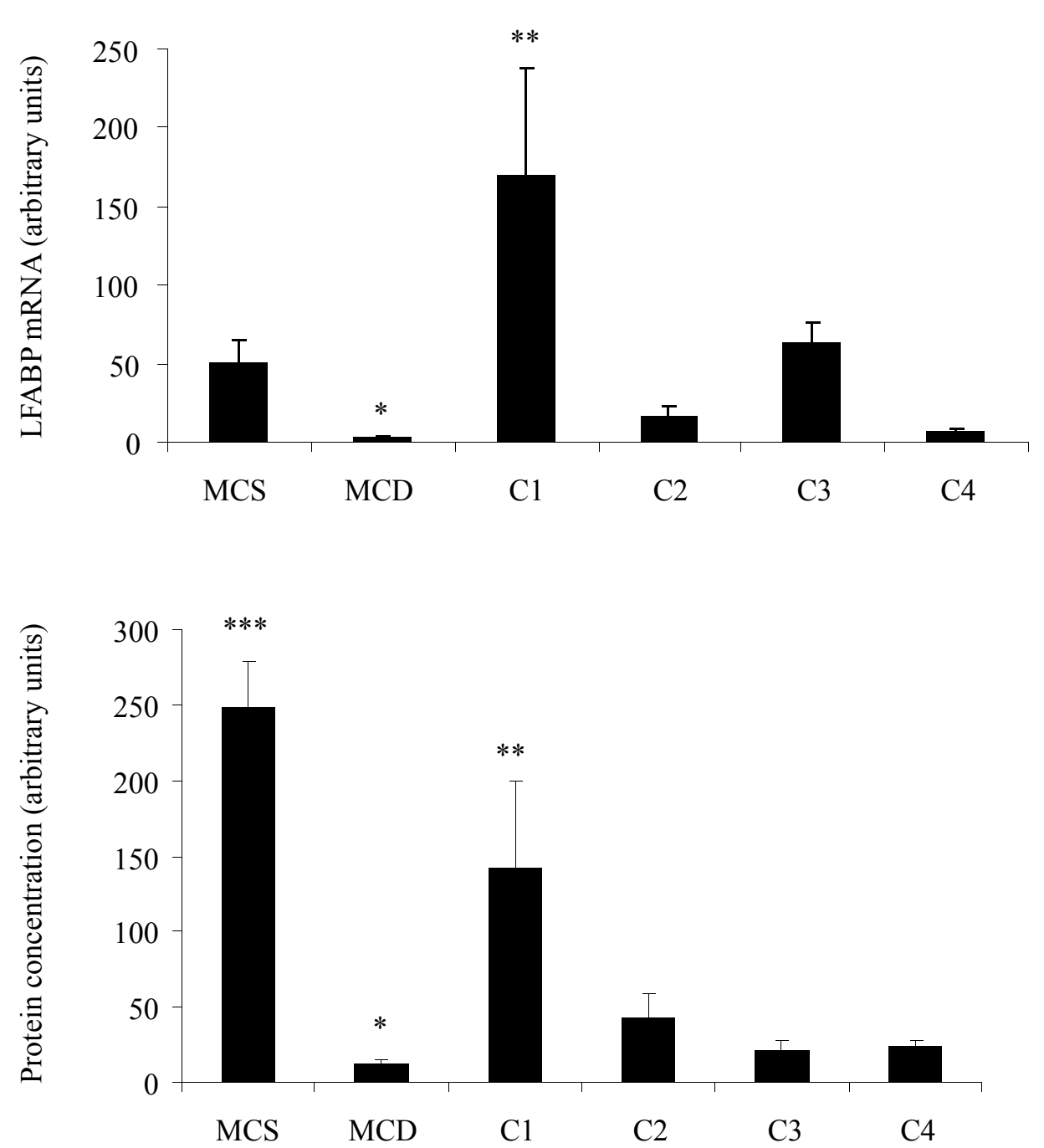

\section{LFABP}

$\beta$-actin

Figure 2 Quantification of LFABP at the mRNA and protein levels. (A) LFABP mRNA levels. (B) LFABP protein concentration. *Significant difference compared to MCS, $p<0.001$. ${ }^{*}$ Significant difference compared to MCD, $p<0.01$. ${ }^{* *}$ Significant difference compared to MCD, C2, C3 and $C 4, p<0.001$.

these groups (Table 4). Slightly lower superoxide and 8-OH-2dG levels were seen when animals were on the C3 diet regime. This C3 cocoa group had lower levels of steatosis when compared to MCD, $\mathrm{C} 1$ and $\mathrm{C} 2$ diet regimes. Further to this, lower levels of lobular inflammation and fibrosis were observed in these groups. It cannot be concluded that the higher levels of superoxide seen in the cocoa supplemented diets are as a result of the cocoa instead of the MCD, as the animals supplemented with cocoa were on the MCD 
diet longer than the MCD control group, dependent on the time of cocoa supplementation.

The quantification of mRNA detected differences in the levels of NOX1 mRNA expression, but no change observed in NOX2 and NOX4 mRNA expression between the different diet regimes. NOX1 mRNA expression levels were lower in all groups fed the MCD diet in comparison to those on the MCS diet (Figure 3A). The effect of the dietary regimes on NOX1 protein levels was different to that of mRNA expression levels (Figure 3B),
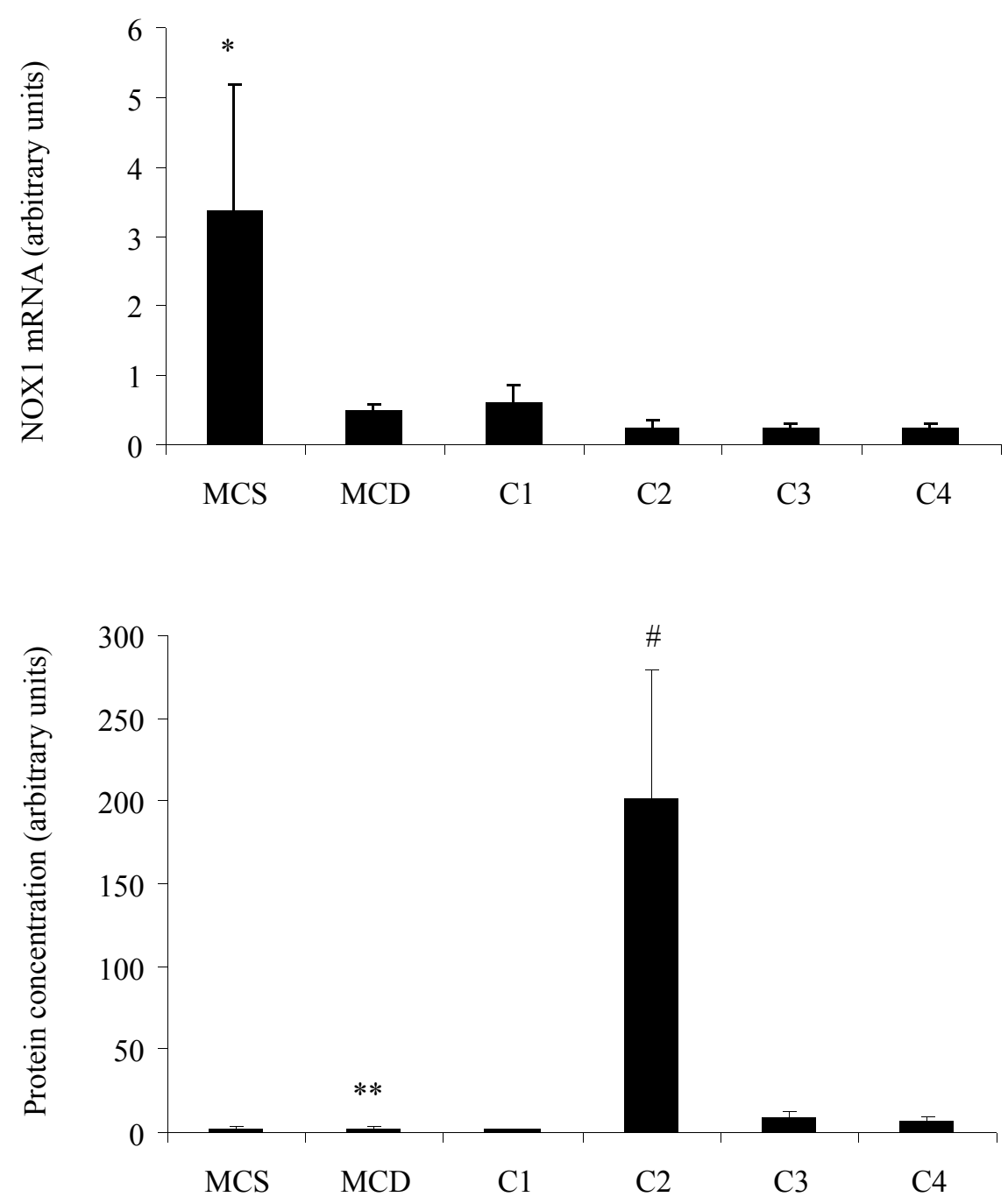

NOX1

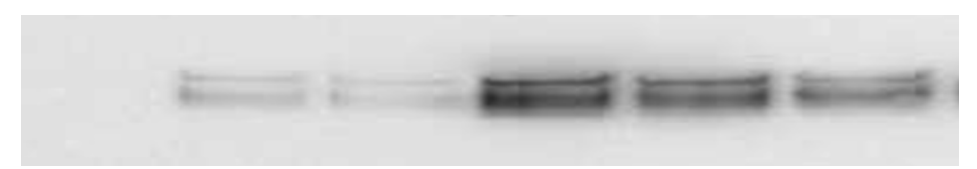

$\beta$-actin

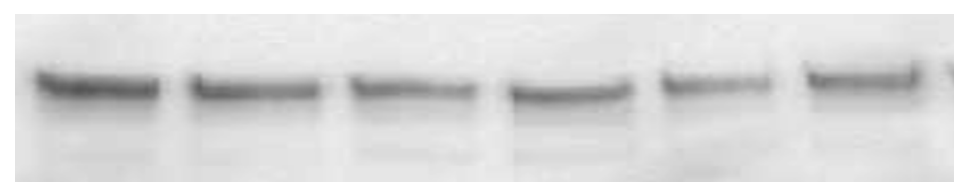

Figure 3 Quantification of NOX1 at the mRNA and protein levels. (A) NOX1 mRNA levels. (B) NOX1 protein concentration. *Significant difference compared to MCS, $p \leq 0.05$. * Significant difference compared to MCD, $p \leq 0.03$. \#Significant difference compared to MCS, MCD, C1, C3 and $C 4, p \leq 0.01$. 
indicating that NOX1 may be regulated at the protein level, rather than the gene level. Higher concentrations of NOX1 protein were observed in animals on the $\mathrm{C} 2$ diet regime. Gene knockout of gp $91^{\text {phox }}$, a vital regulatory component of the assembly of NOX, showed no difference in the pathology of MCD induced NASH in mice compared to wildtype [11]. This would indicate that NOX generation of ROS is not a key factor in the development of MCD induced NASH, which is supportive of our findings in NOX mRNA expression. However, a link can be seen between NOX1 protein levels and presence of portal inflammation in animals on the $\mathrm{C} 2$ diet regime, with higher NOX1 levels measured and a greater proportion of portal inflammation observed in comparison to rats on the other diets. In alcoholic liver disease, mice fed ethanol via the Tsukamoto-French intragastric enteral method, NOX was found to increase ROS and activate $\mathrm{NF}-\kappa \mathrm{B}$, which led to an increase in TNF- $\alpha$ in livers. This leads not only to an increase in oxidative damage but also an increase in synthesis of fatty acids causing hepatic damage [28].

Histological analysis of livers from rats fed the MCD diet showed greater steatosis in comparison to those on the MCS diet (Figure 1). Steatosis has been reported by others at week 2 of MCD feeding in rat livers [7]. The severity of steatosis was not observed to be less in any of the groups in which cocoa was added to the MCD diet, however there was a statistically significant lower degree of steatosis observed in livers of animals fed the C3 diet regime. It is extrapolated from this observation that the antioxidant properties of cocoa are more likely to affect levels of reactive oxidative species rather than hepatocyte fat content. This is supported by a lower level of ROS as determined by DHE staining and 8-OH$2 \mathrm{dG}$ in the $\mathrm{C} 3$ diet regime when compared to $\mathrm{C} 1$ and $\mathrm{C} 2$ diet regimes (Table 5). Antioxidants derived from cocoa may play a role in suppressing the activation of hepatic stellate cells to form fibrotic tissue, as fibrosis was not as severe in the animals on the C3 diet regime, a group which had lower scores for steatosis and lobular inflammation compared to other MCD and MCD/cocoa regimes (Table 4).

Circulating triglyceride levels were lower in the the MCD group compared to the control. However cocoa supplementation was associated with even lower circulating triglyceride levels (Table 5). Re-esterification of fatty acids into triglycerides has been described as a mechanism protecting the liver from lipotoxicity as inflammation, oxidative damage and fibrosis decrease [29]. Lower levels of circulating triglycerides (Table 5) found in our study are in line with increased severity of NAFLD as shown by increased steatosis scores in Table 4. The reduction in body weight on MCD possibly led to an increase in glucose being used as an energy source causing a reduction in the circulating levels of glucose (Table 5). The MCD diet has been previously reported to decrease glucose and improve insulin sensitivity whilst not having a dampening effect on the development of hepatic inflammation or fibrosis [29]. Although the MCD diet caused weight loss, liver weight increased as a result of higher fat content as seen in the histology of these samples (Figure 1; Table 4).

RBC GSH levels were significantly higher in the C1 and $\mathrm{C} 2$ groups (Table 5). This suggested that cocoa could be used to increase the availability of the reduced form of GSH to act as an antioxidant within RBC's and possibly the circulation. Liver GSH on the other hand was much lower in all cocoa supplemented animals when compared to those on the MCS and MCD diets. Low levels of this endogenous antioxidant in the cocoa supplemented animals may be due to the higher bioavailability of exogenous antioxidants derived from the cocoa. The accumulation of exogenous antioxidants from cocoa may therefore be beneficial in providing sufficient antioxidants to quench ROS in NASH. Our findings on hepatic GSH are not in agreement with most other studies which show a depletion of this endogenous antioxidant [7].

Despite the novel data presented from the current study there are limitations associated with the findings. Due to restrictions imposed by the institutional animal welfare committee it was not possible to include additional MCD fed rats for 80 and 108 days to match cocoa supplementation groups $\mathrm{C} 1$ - C4. Although pilot data indicated histologically the livers of rats fed the MCD diet are similar from $42-112$ days, it cannot be excluded that the effects associated with cocoa supplementation in the liver are not to prolonged MCD feeding. It is possible, but unlikely, that the results observed following cocoa supplementation are not due to the antioxidants present in the cocoa, but rather the trace amounts of methionine and choline present in the cocoa. However if the trace amounts of methionine and choline present in the cocoa were responsible for the results observed it would be expected that data collected from the cocoa supplemented groups would more closely resemble the MCS group and not the MCD group. Finally although the MCD diet is a commonly used model of NASH there are a number of limitations associated with comparing the model to metabolic changes in human NAFLD/NASH [7]. These limitations include weight loss in rats fed the MCD diet, whereas NASH patients are typically overweight or obese [1,7]. The accumulation of fat within the liver of rats fed the MCD diet is due to a disruption of the export of hepatic lipids and subsequent lipotoxicity, unlike the human situation where the excessive hepatic fat import or storage is thought to occur $[1,7]$. 


\section{Conclusions}

Our investigations indicate that the intracellular lipid transporter LFABP may play a key role in the establishment of MCD induced NAFLD and NASH not only by shuttling long chain fatty acids within the cell, but possibly by also acting as an antioxidant. Furthermore, the decreased levels of LFABP in the MCD model of NASH may suggest impairment in the functioning of LFABP in this disease. A cocoa rich diet is able to act as a rich source of exogenous antioxidants with no depletion of RBC GSH. However, this does not lead to lower hepatic superoxide and 8-OH-2dG levels. During the supplementation with the $\mathrm{C} 1$ diet regime, cocoa was associated with higher levels of LFABP compared to the MCD diet. There is depletion in the levels of NOX1 mRNA in animals on the MCD diet. NOX1 however is higher at the protein level in the animals on the $\mathrm{C} 2$ regime. The $\mathrm{C} 2$ regime simultaneously increased steatosis, portal inflammation and fibrosis, suggesting a possible role for NOX in inflammation and fibrosis in the rat NASH liver. As NASH develops in humans suffering from obesity and insulin resistance, further investigations into LFABP in the development of NASH in these patients is warranted. As fibrosis was less prominent in animals on the C3 diet regime, the role of antioxidants in influencing stellate cell activation and the development of fibrosis should be investigated.

\section{List of abbreviations}

NAFLD: Non alcoholic fatty liver disease; NASH: Non alcoholic steatohepatitis; AST: Aspartate aminotransferase; ALT: Alanine aminotransferase; LFABP: Liver fatty acid binding protein; PPAR a: Peroxisome proliferator activated protein a; NOX: NADPH oxidase; NF-k $\beta$ : Nuclear factor $\mathrm{k} \beta$; TNF a: Tumor necrosis factor a: MCD: Methionine choline deficient: MCS: Methionine choline sufficient; H\&E: Haematoxylin and Eosin; RBC: Red blood cell; GSH: Glutathione; DHE: Dihydroethidium; ROS: Reactive oxygen species; 8-OH-2dG: 8-hydroxy-2-deoxy Guanosine.

\section{Acknowledgements}

This research was supported by Deakin University and Victoria University. MJ was the recipient of a Deakin University postgraduate scholarship. The authors would like to thank the staff of the Deakin University Building Lp Animal House for their help and support with the animal study and Dr Richard Standish for grading histological samples.

\section{Author details}

${ }^{1}$ School of Medicine, Deakin University, Waurn Ponds, Australia. ${ }^{2}$ School of Biomedical Science, Victoria University, Melbourne, Australia. ${ }^{3}$ School of Sport and Science, Victoria University, Melbourne, Australia.

\section{Authors' contributions}

MJ participated in the design of the study, carried out the analysis and interpretation of data and drafted the manuscript. KNA contributed to the interpretation of data and revised the manuscript. MJS-G carried out the analysis and interpretation of data and drafted the manuscript. MAM carried out the analysis and interpretation of data and drafted the manuscript. PAL participated in the design of the study, Carried of histological grading, contributed to the interpretation of data and revised the manuscript. All authors read and approved the final manuscript.

\section{Competing interests}

The authors declare that they have no competing interests.

Received: 14 March 2011 Accepted: 14 November 2011

Published: 14 November 2011

\section{References}

1. Petta S, Muratore C, Craxi A: Non-alcoholic fatty liver disease pathogenesis: the present and the future. Dig Liver Dis 2009, 41:615-625 2. Bataller R, Brenner DA: Liver fibrosis. J Clin Invest 2005, 115:209-218.

3. Pusl T, Wild N, Vennegeerts T, Wimmer R, Goke B, Brand S, Rust C: Free fatty acids sensitize hepatocytes to bile acid-induced apoptosis. Biochem Biophys Res Commun 2008, 371:441-445.

4. Chitturi S, Farrell GC, Hashimoto E, Saibara T, Lau GK, Sollano JD: Nonalcoholic fatty liver disease in the Asia-Pacific region: definitions and overview of proposed guidelines. J Gastroenterol Hepatol 2007, 22:778-787.

5. Rector RS, Thyfault JP, Wei Y, Ibdah JA: Non-alcoholic fatty liver disease and the metabolic syndrome: an update. World J Gastroenterol 2008, 14:185-192.

6. Day CP, Saksena S: Non-alcoholic steatohepatitis: definitions and pathogenesis. J Gastroenterol Hepatol 2002, 17(Suppl 3):S377-384

7. George J, Pera N, Phung N, Leclercq I, Yun Hou J, Farrell G: Lipid peroxidation, stellate cell activation and hepatic fibrogenesis in a rat model of chronic steatohepatitis. J Hepatol 2003, 39:756-764.

8. Martin GG, Atshaves BP, McIntosh AL, Payne HR, Mackie JT, Kier AB, Schroeder F: Liver fatty acid binding protein gene ablation enhances age-dependent weight gain in male mice. Mol Cell Biochem 2009, 324:101-115.

9. Yan J, Gong Y, She YM, Wang G, Roberts MS, Burczynski FJ: Molecular mechanism of recombinant liver fatty acid binding protein's antioxidant activity. J Lipid Res 2009, 50:2445-2454.

10. Kono H, Rusyn I, Yin M, Gabele E, Yamashina S, Dikalova A, Kadiiska MB, Connor HD, Mason RP, Segal BH, et al: NADPH oxidase-derived free radicals are key oxidants in alcohol-induced liver disease. $J$ Clin Invest 2000, 106:867-872.

11. dela Pena A, Leclercq IA, Williams J, Farrell GC: NADPH oxidase is not an essential mediator of oxidative stress or liver injury in murine MCD dietinduced steatohepatitis. J Hepatol 2007, 46:304-313.

12. de Alwis NM, Day CP: Non-alcoholic fatty liver disease: the mist gradually clears. J Hepatol 2008, 48(Suppl 1):S104-112.

13. Lotito SB, Actis-Goretta L, Renart ML, Caligiuri M, Rein D, Schmitz HH, Steinberg FM, Keen CL, Fraga CG: Influence of oligomer chain length on the antioxidant activity of procyanidins. Biochem Biophys Res Commun 2000, 276:945-951.

14. Matsui N, Ito R, Nishimura E, Yoshikawa M, Kato M, Kamei M, Shibata H, Matsumoto I, Abe K, Hashizume S: Ingested cocoa can prevent high-fat diet-induced obesity by regulating the expression of genes for fatty acid metabolism. Nutrition 2005, 21:594-601.

15. Grassi D, Necozione S, Lippi C, Croce G, Valeri L, Pasqualetti P, Desideri G, Blumberg JB, Ferri C: Cocoa reduces blood pressure and insulin resistance and improves endothelium-dependent vasodilation in hypertensives. Hypertension 2005, 46:398-405.

16. McKim SE, Konno A, Gabele E, Uesugi T, Froh M, Sies H, Thurman RG, Arteel GE: Cocoa extract protects against early alcohol-induced liver injury in the rat. Arch Biochem Biophys 2002, 406:40-46.

17. Kleiner DE, Brunt EM, Van Natta M, Behling C, Contos MJ, Cummings OW, Ferrell LD, Liu YC, Torbenson MS, Unalp-Arida A, et al: Design and validation of a histological scoring system for nonalcoholic fatty liver disease. Hepatology 2005, 41:1313-1321.

18. Pastore A, Federici G, Bertini E, Piemonte F: Analysis of glutathione: implication in redox and detoxification. Clinica chimica acta 2003, 333:19-39.

19. Serrander L, Cartier L, Bedard K, Banfi B, Lardy B, Plastre O, Sienkiewicz A, Forro L, Schlegel W, Krause KH: NOX4 activity is determined by mRNA levels and reveals a unique pattern of ROS generation. Biochem J 2007 406:105-114.

20. Schmittgen TD, Zakrajsek BA, Mills AG, Gorn V, Singer MJ, Reed MW: Quantitative reverse transcription-polymerase chain reaction to study mRNA decay: comparison of endpoint and real-time methods. Anal Biochem 2000, 285:194-204 
21. Nan YM, Wu WJ, Fu N, Liang BL, Wang RQ, Li LX, Zhao SX, Zhao JM, Yu J: Antioxidants vitamin $\mathrm{E}$ and 1-aminobenzotriazole prevent experimental non-alcoholic steatohepatitis in mice. Scand J Gastroenterol 2009, 44:1121-1131

22. Martin GG, Atshaves BP, Huang H, McIntosh AL, Williams BJ, Pai PJ, Russell DH, Kier AB, Schroeder F: Hepatic phenotype of liver fatty acid binding protein gene-ablated mice. Am J Physiol Gastrointest Liver Physiol 2009, 297:G1053-1065.

23. Rajaraman G, Wang GQ, Yan J, Jiang P, Gong Y, Burczynski FJ: Role of cytosolic liver fatty acid binding protein in hepatocellular oxidative stress: effect of dexamethasone and clofibrate treatment. Mol Cell Biochem 2007, 295:27-34

24. Musso G, Gambino R, Cassader M: Non-alcoholic fatty liver disease from pathogenesis to management: an update. Obes Rev 2010, 11:430-445.

25. Skrtic S, Carlsson L, Ljungberg A, Linden D, Michalik L, Wahli W, Oscarsson J: Decreased expression of peroxisome proliferator-activated receptor alpha and liver fatty acid binding protein after partial hepatectomy of rats and mice. Liver Int 2005, 25:33-40.

26. Lewandowski P, Cameron-Smith D, Moulton K, Walder K, Sanigorski A, Collier GR: Disproportionate increase of fatty acid binding proteins in the livers of obese diabetic Psammomys obesus. Ann N Y Acad Sci 1997 827:536-540.

27. Bioulac-Sage P, Laumonier H, Laurent C, Zucman-Rossi J, Balabaud C: Hepatocellular adenoma: what is new in 2008. Hepatol Int 2008, 2:316-321.

28. Kono H, Rusyn I, Uesugi T, Yamashina S, Connor HD, Dikalova A, Mason RP, Thurman RG: Diphenyleneiodonium sulfate, an NADPH oxidase inhibitor, prevents early alcohol-induced liver injury in the rat. Am J Physiol Gastrointest Liver Physiol 2001, 280:G1005-1012.

29. Yamaguchi K, Yang L, McCall S, Huang J, Yu XX, Pandey SK, Bhanot S, Monia BP, Li YX, Diehl AM: Inhibiting triglyceride synthesis improves hepatic steatosis but exacerbates liver damage and fibrosis in obese mice with nonalcoholic steatohepatitis. Hepatology 2007, 45:1366-1374

doi:10.1186/1476-5926-10-10

Cite this article as: Janevski et al.: The effect of cocoa supplementation on hepatic steatosis, reactive oxygen species and LFABP in a rat model of NASH. Comparative Hepatology 2011 10:10.

\section{Submit your next manuscript to BioMed Central and take full advantage of:}

- Convenient online submission

- Thorough peer review

- No space constraints or color figure charges

- Immediate publication on acceptance

- Inclusion in PubMed, CAS, Scopus and Google Scholar

- Research which is freely available for redistribution

Submit your manuscript at www.biomedcentral.com/submit 